RESEARCH PAPER RP1359

Part of Journal of Research of the National Bureau of Standards, Volume 26, January 1941

\title{
SURFACE CHARACTERISTICS OF COTTON FIBERS, AS INDICATED BY ELECTROPHORETIC STUDIES ${ }^{1}$
}

\author{
By Arnold M. Sookne and Milton Harris ${ }^{2}$
}

\section{ABSTRACT}

The surface characteristics of cotton fibers were investigated by a microelectrophoretic technique. Samples of dewaxed cotton, cotton which had been depectinized by treatment with a boiling 1-percent solution of sodium hydroxide for various lengths of time, and pectic substance from cotton gave widely different $\mathrm{pH}$-mobility curves. The curve for pectic substance is characteristic of a highly acidic substance, whereas that for depectinized cotton shows a low order of acidity. The curve for dewaxed cotton appears to be a composite of the curves for cellulose and pectic substance.

The purified cellulose exhibits a reversal of charge below $\mathrm{pH} 2.5$, and accordingly is isoelectric at that $\mathrm{pH}$. It is shown that the reversal of charge has not resulted from irreversible changes produced in the fiber during immersion in the dilute solutions of acid used in the present investigation.

\section{CONTENTS}

Page

I. Introduction

II. Materials and methods

1. Materials _... 66

2. Methods

III. Experiments and discussion

IV. References

\section{INTRODUCTION}

Recent studies on cotton have indicated that the pectic substance occurs principally on the surface of the fiber as part of the primary cell wall $[1,2,3] .^{3}$ Although this substance is present to the extent of only approximately 1 percent, it nevertheless accounts for about 85 percent of the acidic groups in mature fibers. The remainder of the acidic groups, about 15 percent, is presumably associated with the cellulose itself [4]. The highly acidic nature and the location of the pectic substance in the naturally occurring fibers would be expected to influence greatly a number of the properties of the fiber, especially those dependent on surface characteristics. These surface characteristics are of considerable importance in a number of industrial processes, as, for example, the scouring, dyeing, and finishing of textile materials.

The electrophoretic technique has been shown in this laboratory to be a useful tool for characterizing and distinguishing surfaces of different textile fibers or of fibers of which the surfaces have been altered by different chemical treatments $[5,6]$. Since it would be

1 This paper was presented before the Cellulose Division at the 100th meeting of the American Chemical Society, Detroit, Mich.

2 Research Associates at the National Bureau of Standards, representing the Textile Foundation.

3 Figures in brackets indicate the literature references at the end of this paper. 
expected that the surface of a cotton fiber might also be appreciably changed by treatments which are known to remove pectic substance, it appeared that electrophoretic measurements would be of considerable aid in evaluating such changes.

\section{MATERIALS AND METHODS}

\section{MATERIALS}

Raw cotton was extracted with alcohol at room temperature for 24 hours, and then with ether for 24 hours. This will henceforth be described as "dewaxed cotton."

A portion of the dewaxed material was further purified by extraction for 2, 4, 8, or 16 hours with a boiling 1-percent solution of sodium hydroxide, according to the method recommended for the preparation of standard cellulose. The procedure was essentially the same as that described by Corey and Gray [7], except that the apparatus of Worner and Mease was employed [8]. It has been shown by Whistler, Martin, and Harris, that this treatment removes all measurable amounts of pectic substance from cotton [9].; Samples purified in this way will be termed "depectinized cotton."

All of the above samples were reduced to a convenient particle size by grinding them in a laboratory Wiley mill until they passed through a 60 -mesh screen. The powder was suspended in water, the larger particles were allowed to settle, and the particles (1 to 5 microns) remaining in the supernatant liquid were used for the measurements.

Pectic substance was obtained by treating dewaxed cotton with a solution of sodium hexametaphosphate, shown elsewhere [10] to separate readily the pectic substance from cotton. The procedure was as follows: $100 \mathrm{~g}$ of dewaxed cotton was soaked at room temperature for 7 hours in 1 liter of a 0.5 -percent solution of sodium hexametaphosphate at $\mathrm{pH}$ 7.9. The liquid was pressed out, and the cotton was soaked overnight in an additional 1-liter portion of the same solution. The combined solutions were dialyzed against running distilled water for 2 days. Hydrochloric acid and potassium chloride were added to portions of the solution until the final ionic strength was $0.02 \mathrm{M}$ at $\mathrm{pH}$ values from 1.7 to 4.1 . Microscopically visible particles suitablefor mobility measurements were found to be suspended in the acidified solutions.

\section{METHODS}

The electrophoretic technique was the same as that used in earlier studies on silk [5] and wool [6] fibers. An Abramson microelectrophoresis cell was used for the measurement of electric mobility [11]. The methods suggested by Moyer were followed in detail [12]. When the mobilities were very low, which was the case for all of the depectinized samples, the velocities of the particles were measured in successive layers from the top to the bottom of the cell, and the mobility was evaluated by graphical integration of the curve obtained by plotting velocity against depth [11].

Preliminary measurements showed that throughout the range of $\mathrm{pH}$ investigated, there was no appreciable change of the mobility of the pectic substance or of the dewaxed or depectinized cotton when suspensions were allowed to stand from 15 minutes to 24 hours before mobility measurements were made. 
The $\mathrm{pH}$ values of the suspensions were measured with a McInnes and Belcher-type glass electrode and a vacuum-tube potentiometer, using a cathode-ray tube as null indicator. The $\mathrm{pH}$ values were referred to potassium acid phthalate, $0.05 M$, to which was assigned a $\mathrm{pH}$ value of 4.01 [13].

\section{EXPERIMENTS AND DISCUSSION}

Curve 5, figure 1, shows the $\mathrm{pH}$-mobility curve for pectic substance. The curve is typical of that of a highly acidic substance, since the particles exhibit a large negative charge even at $\mathrm{pH}$ 1.7. This is consistent with the results of an earlier investigation, which showed that the entire uronic acid-carboxyl content of the pectic substance was present in the form of titratable carboxyl groups [4]. The $\mathrm{pH}-$

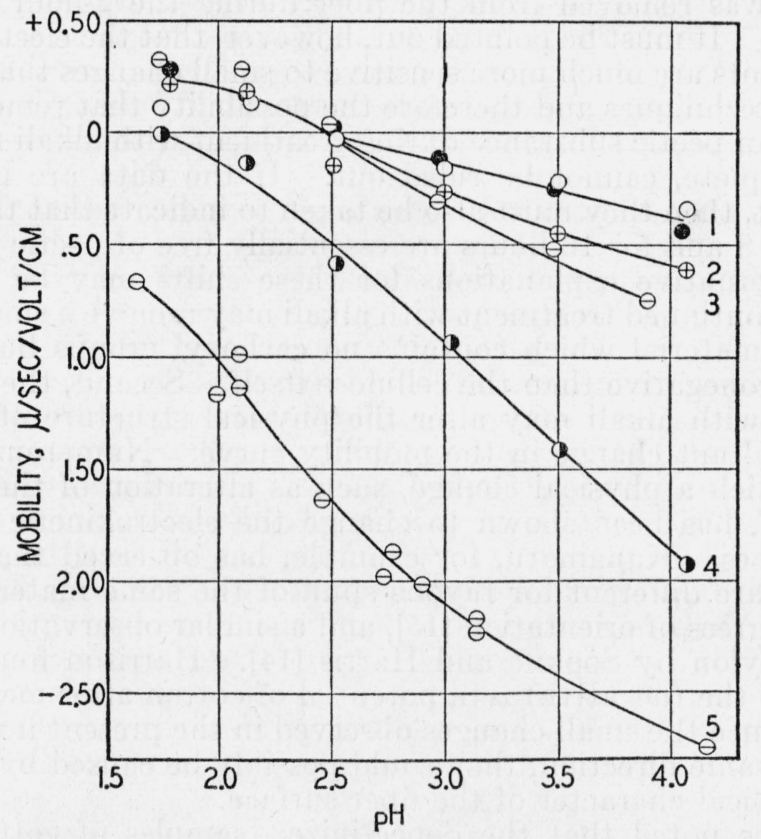

Figure 1. - A comparison of the $\mathrm{pH}-$ mobility curves for dewaxed cotton, depectinized cotton, and pectic substance from cotton.

Curve 5 represents the mobility of the pectic substance. Curve 4 is that for dewaxed cotton. Curve 3 is that for cotton treated with boiling 1-percent $\mathrm{NaOH}$ for 2 hours. Curve 2 is for cotton similarly treated for 4 hours. Curve 1 is for cotton treated for 8 (open circles) and for 16 hours (filled circles).

mobility curve for dewaxed cotton (curve 4) is similar in shape to that for the pectic substance, but the material is shown by the shift in the curve along the axis of ordinates to be less acidic than the pectic substance. If the particles of dewaxed cotton were completely coated with pectic substance, a curve identical with curve 5 would have been obtained. The results suggest that cutting the fibers exposes new surfaces which are presumably cellulosic, and since these are much less acidic than the pectic substance itself, the number of acidic groups per unit surface has accordingly been decreased. It would appear then 
that curve 4 is a composite of the curves for the highly acidic pectic substance and the much less acidic cellulose.

The $\mathrm{pH}$-mobility curve of a sample of depectinized cotton, prepared by treating dewaxed cotton for 2 hours with a boiling 1-percent solution of alkali, is shown in curve 3. Its position relative to the curve for dewaxed cotton indicates the removal of an acidic component. Slight further shifts in the $\mathrm{pH}$-mobility curve were caused by 4 hours (curve 2) and 8 hours (curve 1) of extraction with the alkali, but these last effects are much smaller. A sample treated for 16 hours gave no further change in the $\mathrm{pH}$-mobility curve (curve 1).

The small shifts in the positions of the $\mathrm{pH}$-mobility curves for samples of cotton treated for 4 and for 8 hours were somewhat surprising, especially since earlier determinations of uronic acid [9] as well as titration studies [4] had indicated that essentially all of the pectic substance was removed from the fiber during the 2-hour treatment with alkali. It must be pointed out, however, that the electrophoretic measurements are much more sensitive to small changes than either of the above techniques and therefore the possibility that removal of the last traces of pectic substance during treatment with alkali for 2 hours is not complete, cannot be ruled out. If the data are interpreted in this light, then they must also be taken to indicate that the samples treated for 8 and for 16 hours are essentially free of pectic substance.

Two alternative explanations for these shifts may be advanced. First, the continued treatment with alkali may remove a small amount of surface material which contains no carboxyl groups but which is more electronegative than the cellulose itself. Second, the continued treatment with alkali may alter the physical structure of the fiber, with a resultant change in the mobility curve. Numerous instances exist in which a physical change, such as alteration of the degree of orientation, has been shown to change the electrokinetic properties of substances. Kanamaru, for example, has observed that the zeta potentials are different for rayons spun of the same material, but of varying degrees of orientation [15], and a similar observation has been made on nylon by Sookne and Harris [14]. Harrison found a large decrease in the (negative) zeta potential of cotton after mercerization [16], and since the small changes observed in the present investigation are in the same direction, they could possibly be caused by alteration of the physical character of the fiber surface.

It will be noted that the depectinized samples of cotton exhibit reversal of charge below about $\mathrm{pH} 2.5$ and accordingly are isoelectric at that $\mathrm{pH}$. However, it has been reported [17] that cellulose has no true isoelectric point and that reversal of the charge in the more acid solutions resulted from hydrolysis at the surface of the fiber. Although these conclusions arose from investigations on wood cellulose, it nevertheless appeared advisable to determine whether any irreversible effects had been produced under the conditions of the present studies. For this purpose, the following experiments were performed. $1.5-\mathrm{g}$. samples of ground, depectinized ( 8 hour) cotton were soaked in 400-ml portions of hydrochloric acid-potassium chloride solutions $(0.02 \mathrm{M}$ ionic strength) having $\mathrm{pH}$ values of 1.7, 2.5, and 3.3. These solutions were identical with those used in obtaining the data shown in figure 1 . After 1 hour, the samples were filtered off on a sintered glass funnel and thoroughly washed with running distilled water. Water sus- 
pensions of each of the three samples as well as of a sample of the untreated, depectinized cotton were then prepared and sufficient acetic acid and sodium acetate added to bring the $\mathrm{pH}$ value of each solution to 5.6 and the ionic strength to $0.005 M$. The samples were allowed to remain in contact with the buffer solutions for 24 hours, after which the mobilities of the particles were measured. No significant differences between the acid-treated and untreated samples were found and therefore it was concluded that no irreversible changes in the surface potential of cotton were produced by the dilute solutions of acid employed in the present work.

\section{REFERENCES}

[1] R. L. Whistler, A. R. Martin, and M. Harris, J. Research NBS 24, 555 (1940) RP1299; Am. Dyestuff Reptr. 29, 244 (1940); Textile Research 10, 269 (1940).

[2] C. W. Hock and M. Harris, J. Research NBS 24, 743 (1940) RP1309, Am. Dyestuff Reptr. 29, 287 (1940); Textile Research 10, 323 (1940).

[3] D. B. Anderson and T. Kerr, Ind. Eng. Chem. 30, 48 (1938).

[4] A. M. Sookne and M. Harris, J. Research NBS 25, 47 (1940) RP1313; Am. Dyestuff Reptr. 29, 357 (1940); Textile Research 10, 405 (1940).

[5] A. M. Sookne and M. Harris, J. Research NBS R3, 299 (1939) RP1234; Am. Dyestuff Reptr. 28, 412 (1939); Textile Research 9, 374 (1939).

[6] A. M. Sookne and M. Harris, J. Research NBS 23, 471 (1939) RP1245; Am. Dyestuff Reptr. 28, 593 (1939); Textile Research 9, 437 (1939).

[7] A. B. Corey and H. LeB. Gray, Ind. Eng. Chem. 16, 853, 1130 (1924).

[8] R. K. Worner and R. T. Mease, J. Research NBS 21, 609 (1938) RP1146.

[9] R. L. Whistler, A. R. Martin, and M. Harris, J. Research NBS 24, 13 (1940) RP1268; Am. Dyestuff Reptr. 29, 1 (1940); Textile Research 10, 109 (1940). [10] In preparation for publication.

[11] H. A. Abramson, Electrokinetic Phenomena (The Chemical Catalog Co., New York, N. Y., 1934).

[12] L. S. Moyer, J. Bact. 31, 531 (1936).

[13] D. I. Hitchcock and A. C. Taylor, J. Am. Chem. Soc. 60, 2710 (1938).

[14] A. M. Sookne and M. Harris. (In preparation.)

[15] K. Kanamaru and T. Takada, Z. physik. Chem. A186, 1 (1940).

[16] W. Harrison, J. Soc. Dyers Colourists 27, 279 (1911).

[17] A. J. Stamm, Colloid Symposium Monograph 5, 361 (1927).

Washington, October 8, 1940. 